\section{THE MOTOR FUNCTIONS OF THE STOMACH.}

To the Editor of THE LANCET.

SIR,-In one of Mr. H. M. W. Gray's papers on the "Motor Functions of the Stomach," published in THE LANCET of 1908, he ascribes the discovery of secretin to Wertheimer, without even mentioning the names of Bayliss and Starling. As this is only one example of numerous inaccuracies in the papers, it is surprising that they evoked no public criticism at the time. As, however, there is a danger of frequently repeated errors being finally accepted as facts, it is desirable that some of the mistakes in Mr. Gray's recent article in THE LANCET of Dec. 3rd should be corrected.

My first observations on the human stomach with the $\mathrm{X}$ rays were made in the horizontal position, and I was ledlike Mr. Gray-to believe that the stomach is divided into two parts, anatomically and functionally distinct. When I began to examine the stomach in the vertical position also, I soon found that I kad been mistaken, and I am now convinced that there is no such thing as a "middle sphincter." It would occupy too much space to give my reasons in detail but I may refer Mr. Gray to my paper on the subject in the Quarterly Journal of Medicine for July, 1910.

It is easy to see with the $\mathrm{X}$ rays that peristalsis begins near the centre of the stomach, where it produces a shallow depression, which increases in depth as it moves towards the pylorus. When it reaches the pyloric vestibule the depression is so great that it almost completely divides the stomach into two parts, but the wave still moves on, and the division is absent in the intervals between the arrival of successive peristaltic waves. When death occurs during digestion the depression produced by a peristaltic wave may be fixed at the point where it happened to be at the moment of death : it is this depression which has been mistaken in anatomical preparations for a third sphincter.

The idea that there is a sharp separation between the chemical processes occurring in the two ends of the stomach is also incorrect. The food taken at the beginning of a meal reaches the pyloric end first, and that taken last is at first uppermost. Some hydrochloric acid, which is secreted mainly in the cardiac end, is carried with the first part of the meal to the pyloric end, where gastric juice and food are thoroughly mixed together by the peristalsis. It is now universally acknowledged (except by Mr. Gray) that there is no peristalsis in the cardiac end; consequently the peripheral part of the food is most acid and the central part may remain for a time alkaline and undergo salivary digestion (Grützner, Cannon). The moderately acid contents of the pyloric end, the very acid food in contact with the mucous membrane of the cardiac end, and the alkaline food in its centre are quite indefinitely separated from each other, as diffusion of the saliva and soluble constituents of the food on the one hand, and of gastric juice and products of gastric digestion on the other, must constantly and rapidly take place, and the movements of the diaphragm, abdominal muscles, and body as a whole all help to mix together the contents of the different parts of the stomach.

I should be glad to know the names of Mr. Gray's " recent radiographers and others" who " assert that the pylorus during gastric digestion descends naturally below and to the left of the umbilicus." In normal individuals I have never seen it either below or to the left of the umbilicus, and all the recognised authorities on the subject, including Barclay, Pfahler, Rieder, Holzknecht, Leven and Barret, Censé and Delaforge, are in agreement with me.

And who are the "recent radiographers" who say that "carbohydrate food begins to pass through the pyloru (displaced as described) in 15 to 20 minutes, and proteid in 30 to 45 minutes"? These are the figures given by Cannon as a result of his observations on cats, but it is now admitted by all who have examined human beings with the $\mathrm{X}$ rays that food, whatever its nature, begins to pass through the pylorus at once, and that a considerable quantity can be seen in the small intestine-and even sometimes in its pelvic portion-within a quarter of an hour. Yet Mr. Gray states that the times quoted are "the times when he observes food beginning to pass through the 'middle sphincter' and he gravely suggests that "these gentlemen (i.e., 'the radiographers and others ') mistake the 'middle sphincter' for the pylorus"। What Mr. Gray mistakes for a middle sphincter is beyond $\mathrm{my}$ power of imagination.

I quite fail to understand how the relief of hunger pain is evidence in favour of a middle sphincter. If it really prevented the access of food into the pyloric end of the stomach the eating of more food ought to be without influence on the pain. As a matter of fact, I have been able to demonstrate to the satisfaction of Mr. Moynihan ${ }^{1}$ that food leaves the stomach with unusual rapidity in cases of duodenal ulcer, and that the delay in the onset of pain is not due to food being held back by the pylorus or by Mr. Gray's sphincter. My observations are confirmed by Barclay, who states that " the picture of a normal stomach exhibiting excessive peristalsis and passing the food on very rapidly is always suggestive of trouble in or about the duodenum."

Mr. Gray can never have seen intestinal segmentation or the interesting appearances recently described by Dr. Barclay of "blobs of food" dropping into the lower part of an atonic stomach, or he would not have rejected the entirely satisfactory explanation offered by Dr. Barclay himself, and made the extraordinary suggestion that the latter is due to segmentation, to which it does not bear even the remotest resemblance.

I am, Sir, yours faithfully,

Weymouth-street, W., Dec. 5th، $1910 . \quad$ ARTHUR F. HERTz.

\section{THE OWNERSHIP OF MEDICAL PRESCRIPTIONS. \\ 曋 To the Editor of THE LANCET.}

SiR,-The law has been declared by an eminent official to be "a ass" ; it is comforting therefore to find that it may be occasionally in accordance with common-sense. I think that the opinion on the subject of prescriptions given by Mr. H. Wippell Gadd ${ }^{2}$ may, on the whole, though it is not quite free from ambiguity, be so designated. It is gratify. ing to have legal authority for the tenet that the purpose of a prescription is "limited in time as well as in person." The ambiguity lies in the statement that the prescription, though conditionally, "becomes the absolute property of the person who has paid the fee." What is the meaning of "prescrip. tion" here? Is it merely a piece of paper or is it an instrument that can be used for further purposes? It seems to me that there is some analogy between a prescription and a cheque. A cheque is written to empower a banker to pay a certain sum of money to a certain person; a prescription is written to empower a chemist to prepare a certain medicament for a certain person. When the cheque has been presented and cashed, it becomes invalid and useless; it is retained by the banker though it remains the property of the drawer and may be returned to him if required as a voucher of receipt. When a prescription has been made up, the document is sometimes retained by the chemist, but is usually returned to the patient. If it were still of any use to the prescriber I have no doubt that he would claim it and have it restored to him ; but it would be to him valueless, only waste paper. There is some reason for the chemist to retain it, in case any doubt might arise as to the correctness of the writing or of the dispensing of it, although a copy, which he nsually makes, is almost always sufficient. But on the whole, unless it be destroyed, it is perhaps best for the patjent to retain the document (though he must be prevented from misusing it), as he may want it made up first in one place and then in another before its period expires, when it becomes as useless as the cashed cheque. Also he may sometimes bave occasion to refer to it on subsequent occasions-e.g., to show to another medical man what treatment he had received before. For instance, some time ago I was treating a patient with pot. iodid. in moderate doses with moderate success; he told me that he had previously derived much benefit from very large doses. I acted on the hint with complete success.

I think that Mr. Gadd suggests the best road out of the difficulty, and one wbich, if generally followed, will lead to success. The proper way to limit the time of the prescription (after which it is, or should be, as dead as a cashed cheque) is, I believe, that which I have adopted for some time and to which I alluded in a letter published in

1 B. G. A. Moynihan: Duodenal Ulcer, p. 108 ; London, 1910. 
THE LaNCET on Oct. 31st, 1908-viz, to print conspicuously on the face of every prescription, "Not to be repeated after ...... days." This seems to be quite in accordance with Mr. Gadd's ideas, when he speaks of "the directions on the face of a prescription" which pharmacists would "respect and faithfully observe." This direction of a timelimit ought, I maintain, to be given on every prescription. If generally adopted its propriety would be readily acknowledged. A direction, " Rep. ad lib.," would be an exception. Limitation as to time would also almost entirely prevent transference of a prescription to others-e.g., in such a case as this : A patient has a prescription given to him (or her) by a physician in England; he afterwards comes to Australia and has it repeatedly made up there and distributes it among bis (or, of course, usually her) friends, some of whom it may suit, others may be unaffected, to others it may be noxious. Thus it would be hardly necessary to express a limitation to the individual patient on the face of the prescription.

If a prescription is seized and made improper use of by a quack the way to deal with such action is by an Act for the suppression or limitation of quackery. There is another point wherein I think that prescriptions should be improved by greater strictness. Instead of having a mere unrecognisable hieroglyphic representing the initials of the prescriber, who is possibly and probably quite unknown to the dispenser, his name, titles, and address ought to be written or printed plainly on the face of the prescription, so that he may be identified. I am, Sir, yours faithfully, - F. Lucas BenhaM, M.D., B.S. Lond., M.R.C.P. Lond. Exeter, South Australia, Nov, 1st, 1910.

\section{POLYDACTYLISM AND HEREDITY.}

\section{To the Editor of THE LANCET.}

SIR,-The following cases of polydactylism may be of interest to your readers. A woman, aged 40 years, who had an extra finger on each hand and an extra toe on each foot bad six children, all girls. Five of these showed the deformity in a greater or less degree. Given in order of age they were affected: (1) right hand and left foot; (2) both feet ; (3) both feet and both hands ; (4) both feet and both hands ; (5) right hand and left foot; the sixth child showed no signs of deformity, and there was no history of any of the relatives of either the mother or father having showed signs of the condition. I am, Sir, yours faithfully,

South Shields, Dec. 3rd, 1910.

A. BANKS RAFFLE.

\section{INVALIDITY INSURANCE.}

To the Editor of THE LANCET.

SIR,-The question of invalidity insurance for the industrial classes is very much in the public mind just now owing to the announcement that the present Government, if returned to office after the election, will introduce such a scheme in the next session of Parliament; and while it is not $\mathrm{my}$ purpose to contribute directly to the discussion of such a scheme, indirectly some facts, which have emerged in the course of my own experience, may prove of more than passing interest to medical men.

It is a striking fact that while mortality is improving invalidity is increasing. The improvement in mortality has been accounted for as follows: (1) the increased protection afforded to infant life; (2) the improvements in sanitary science, which have done much towards averting epidemic and enabling communities to deal more intelligently and efficiently with them when they occur; and (3) the great advances in medical and surgical skill, and the improved treatment of sick at home and in hospitals, which have saved vast numbers from attacks which would otherwise have proved fatal.

The natural conclusion to be drawn from the improvement in mortality would be that there was also less sickness, but it is an indisputable fact that sickness is actually on the increase. It may be that knowledge of the science of public health is teaching men to take precantionary measures, and that one result of these precautions is that people now lie up where previously they would have continued at work. On this assumption there would obviously be, in the first place, an increase in the rate of sickness, and, in the second, a reduced rate of mortality, if only on the principle that "a stitch in time saves nine."

The company with which I am associated originated a system of sickness insurance for professional and business men some 25 years ago, and has therefore auquired a somewhat nnique experience in this department, and the privilege I enjoy of access to their records has enabled me to compile some valuable figures, which go to show that one week of sickness benefit per annum becomes payable to every member assured between the ages of 20 and 35 . Between ages 45 and 50 this payment is increased to two weeks per annum. Between 55 and 60 it works out at over four weeks per annum, and between 60 and 65 to over six weeks per annum. Then nearly 25 per cent. of the members assured are incapacitated for one week at least in each year between the ages of 20 and 40 , and this increases steadily until it reaches 40 -per cent. between the ages of 60 and 65 .

Another feature brought out by an examination of ?the experience referred to is that of the average number: of weeks' pay made to each member who is sick during each year: From 20 to 25 this amounts to nearly four weeks; from 40 to 45 the duration has grown to rather over six weeks; from 50 to 55 it is more than nine weeks; and from 60 to 65 the average duration of sickness is just under 16 weeks.

These figures tell their own story, one part of which that no system of invalidity insurance can be thoroughly sound unless either the rates of premium increase with the increase in age, in which event they would be prohibitive in the later years of life, or, secondly, a fixed premium is charged. This, like a life premium, must be something more in the early ages than is required for the claims at. those ages, the balance being accumulated securely at compound interest, so that the heavier sickness of later life may be met out of this source without an increase in the annual contribution. I imagine that both actuaries and medical men will watch with great interest a development so interest. ing as that foreshadowed in the Government programme. I am, Sir, yours faithfully,

W. A. Robertson, F.F.A.,

Nov, 25th, 1910 Actuary, Century Insurance Company, Edinburgh.

\section{A CORRECTION.}

To the Editor of THE LANCET.

SIR,-The remarks which you kindly made in reference to my work in Suffolk in connexion with the epizootic of plague on p. 1568 of your issue of Nov. 26th err in one particular. In fairness to the gentleman holding the post I ought to tell you that I am not the assistant medical officer of health for Ipswich. Prior to the appointment of an assistant I undertook the work of the medical officer of health in his absence, but now, apart from my appointment by the East Suffolk county council, the only official position I hold is that of bacteriologist to the East Suffolk and Ipswich Hospital. I am, [Sir, yours faithfully,

Ipswich, Dec. 2nd, 1910

H. LLEWELLYN HEATH.

Metropolitan Hospital Sunday Fund.-

Under the presidency of the Lord Mayor, the Right Hon. Sir Thomas Vezey Strong, a council meeting of this Fund was held at the Mansion House on Nov. 30th, when the report for the year 1910 was ordered to be published. The report states that the total collection amounted to $£ 71,550$, of which $£ 40,778$ were collected in places of worship, £1635 more than in 1909. On the motion of Archdeacon Sinclair, the sum allotted by the Fund to the purchase of surgical appliances was raised from 5 per cent. to $7 \frac{1}{2}$ per cent. Referring to the subject of cinematograph shows, Archdeacon Sinclair said that pending the appeal in a certain case by the London County Council with regard to the licensing of these exhibitions, the Fund could not arrive at a decision with regard to these shows being held on Sundays for the benefit of hospitals. He thought, however, that the subcommittee which had the matter in hand would arrive at a satisfactory decision. It was agreed by the council to recommend that the sum of $£ 100$ should be voted to the secretary, Sir Edmund Hay Currie, who is suffering from bronchitis, to enable him to take a holiday abroad, and the sum of $£ 20$ towards a testimonial to Mr. Cole of the Christian Evidence Society. The annual meeting of the Fund will be held on Dec. 16th. 